\title{
Prevention of Iron Deficiency Anemia in Adolescent and Adult Pregnancies
}

\author{
Paul R. Meier, MD, Departments of Obstetrics and Gynecology, Marshfield Clinic, Marshfield, Wisconsin \\ H. James Nickerson, MD, Pediatrics, Marshfield Clinic, Marshfield, Wisconsin \\ Kurt A. Olson, MS, Departments of Epidemiology and Biostatistics, Marshfield Medical Research Foundation, Marshfield, Wisconsin \\ ${ }^{*}$ Current Affiliation, Amgen, Thousand Oaks, California \\ Richard L. Berg, MS, Departments of Epidemiology and Biostatistics, Marshfield Medical Research Foundation, Marshfield, Wisconsin \\ James A. Meyer, MD, Adolescent Medicine, Marshfield Clinic, Marshfield, Wisconsin
}

\section{ABSTRACT}

OBJECTIVE

Worldwide attention over iron deficiency anemia (IDA) in pregnancy has shifted recently from providing supplements during pregnancy to attempting to ensure that women, especially adolescents, have adequate iron stores prior to conception. We sought to determine whether adolescent and/or adult women still need supplements during pregnancy to avoid IDA, even if iron stores are adequate, and whether the IDA translates into maternal and/or infant morbidity and mortality. DESIGN

Randomized, double-blind clinical trial with placebo control.

SETTING

Multicenter clinic setting in central Wisconsin.

PARTICIPANTS

Adolescent women 18 years or less in their first pregnancy, and adult women 19 years or older, who were found to be healthy and iron sufficient at their first prenatal visit.

METHODS

Participants were randomized to receive iron supplementation (60 mg/day elemental iron) or placebo. Serum ferritin of $12 \mathrm{ng} / \mathrm{mL}$ or less with simultaneous hemoglobin of $11 \mathrm{~g} / \mathrm{dL}$ or less defined IDA. When IDA occurred at the second trimester, a therapeutic supplement of $180 \mathrm{mg}$ of elemental iron per day was initiated. RESULTS

Forty-seven percent of all placebo-supplemented and $16 \%$ of all iron-supplemented patients exhibited IDA ( $p<0.001) ; 59 \%$ of adolescent placebo-supplemented and $20 \%$ of adolescent iron-supplemented patients exhibited IDA ( $p=0.021)$. Nausea, vomiting, diarrhea, and constipation were not significantly different in the iron supplemented group compared to the placebo group, and no significant differences were seen in maternal or neonatal health, but the number of women studied was limiting for analysis of these adverse events.

CONCLUSION

IDA is common in healthy, iron-sufficient adolescent pregnant women during the second trimester, and body stores of iron decline in both adolescent and adult pregnancies. The incidence of IDA during adolescent and adult pregnancies is substantially reduced with $60 \mathrm{mg}$ of elemental iron per day. However, there remains no clear evidence that maternal or neonatal health will benefit from correcting these deficits.

RECEIVED: February 15, 2002

REPRINT REQUESTS:

$H$. James Nickerson, MD

Department of Pediatrics

Marshfield Clinic

1000 North Oak Avenue

Marshfield, WI 54449

Email: nickerson.harlan@marshfieldclinic.org
REVISED AND ACCEPTED: September 27, 2002

\section{KEYWORDS:}

Iron deficiency anemia (IDA); Iron deficiency; Iron supplements; Pregnancy

GRANT SUPPORT:

Research was supported by BRSG S07 RR05960-01 awarded by the Biomedical Research Support Grant Program, Division of Research Resources, National Institutes of Health and in part by a grant 128-01-06 from the Marshfield Medical Research Foundation, the Mead-Johnson Nutritional Division, and Hybritech, Inc, San Diego, California. 


\section{INTRODUCTION}

Anemia during pregnancy, particularly iron deficiency anemia (IDA), continues to be of world-wide concern. ${ }^{1-16}$ Iron supplementation in pregnancy is a widely recommended practice, yet intervention programs have met with mixed success and controversies abound. Should supplements be given on a weekly or daily basis? ${ }^{4}$ Should supplements be given to all pregnant women, or only to those with demonstrable anemia? ${ }^{17,18}$ Are there health risks associated with administering excess iron to women who don't need it? ${ }^{4}$ In contrast to severe anemia, does mild to moderate anemia during pregnancy translate into maternal or neonatal morbidity or mortality?4,5,17-20 Should emphasis be placed on building up iron stores prior to conception? ${ }^{21}$ Are adolescents at an increased risk of developing anemia as compared to adults? 5,22

The world's adolescent population (age 10-19 years) is estimated to stand at more than 1 billion, yet adolescents remain a largely neglected, difficult-to-measure, and hard-to-reach population in which the needs of adolescent girls, in particular, are often ignored. ${ }^{5}$ This area of adolescent health has been difficult to study, and there are many unknown factors and consequences for iron deficiency during adolescence in terms of standards, measurement indicators and health consequences.

In 1993, the World Health Organization (WHO) instituted its Safe Motherhood Initiative with a goal of reducing the number of maternal deaths by half before the year $2000 .{ }^{23-25} \mathrm{~A}$ key component was to eradicate anemia in pregnancy, focusing on the greater risk in younger women. In 1997, WHO convened a regional consultation of experts to address malnutrition issues among adolescent girls in South-East Asia. ${ }^{26}$ Among the recommendations for action was a need for the development of assessment, advocacy, prevention, and control initiatives, in most countries, to reduce anemia in adolescent girls. As an outcome, WHO training programs for adolescent nutrition have been initiated.

In 1999, a special symposium entitled "Improving Adolescent Iron Status before Childbearing" was convened in Washington DC. The conclusions of this group were that many girls are already anemic by the time they become pregnant (16-55\%), and that pregnancy is too short a period of time in which to reduce pre-existing anemia, especially when many women do not seek prenatal care until the second or third trimester. ${ }^{27}$ Thus, they concluded that emphasis needs to be placed on pre-pregnancy programs to increase body iron stores.

Others argue that the iron requirements are highest in the second and third trimesters of pregnancy, and that stores are exhausted in most women at this point. 19,28 Therefore, iron balance at this stage depends more on adequate intakes of bioavailable iron than on the size of iron stores at conception. ${ }^{19}$
Adolescence is a time of intense physical, psychosocial, and cognitive development. Increased nutritional needs at this juncture relate to the fact that adolescents gain up to $50 \%$ of their adult weight, more than $20 \%$ of their adult height, and $50 \%$ of their adult skeletal mass during this period. The iron needs are high in adolescent girls because of the increased requirements for expansion of blood volume associated with the adolescent growth spurt and the onset of menstruation. ${ }^{29}$ When pregnancy is interposed during this time, problems of iron balance are compounded. 8,16,19,22,26,27,29 Over half the world's population is under 25 years old, and more than $80 \%$ of the world's youth live in developing countries. ${ }^{5}$ Iron deficits induced by poor diet and disease, along with difficult logistics associated with supplementation programs in developing countries, compound the problem of studying the iron needs during pregnancy in much of the world's population. For these reasons, we felt it important to study a population with adequate diets and normal pre-pregnancy iron stores. We investigated the response to supplemental iron in adolescents and adults throughout the course of normal pregnancies.

\section{METHODS}

Subjects were recruited from obstetrical patients seen for their first prenatal visit at Marshfield Clinic, a private group practice in central Wisconsin. All patients signed informed consent approved by the Institutional Review Board of the Marshfield Medical Research Foundation.

Patients were divided into two groups consisting of adolescents 15 through 18 years of age in their first pregnancy, and adult women 19 years or older in their first or greater pregnancy. While WHO defines adolescents as persons 10-19 years of age, ${ }^{30}$ we chose to use 19 years as a cutoff in order to enhance the chances of detecting an effect of the adolescent growth spurt.

Adolescent or adult women found to have IDA on their first prenatal visit were excluded and offered treatment. Using randomization stratified by age group, eligible adolescent and adult participants were randomized to receive once daily in a double-blind fashion either an oral iron supplement of 200 $\mathrm{mg}$ of ferrous sulphate ( $60 \mathrm{mg}$ elemental iron) or a placebo capsule identical in appearance to the iron supplement. Two hundred twenty-five capsules were issued to each study participant, and the unused iron or placebo capsules were collected at the conclusion of their pregnancy to estimate adherence. Each participant also received $1 \mathrm{mg}$ of folic acid daily ${ }^{31}$ and was asked not to take any other vitamin or mineral preparation during the pregnancy with the exception of fluoride. At 24 to 28 weeks all participants were interviewed by phone by a research nurse to quantify the patient's perception of the occurrence of nausea, vomiting, diarrhea, and constipation in their own pregnancy. 
Laboratory tests were performed upon enrollment in the prenatal program (test 1), again at 24 to 28 weeks (test 2), and finally before delivery at 36 to 40 weeks (test 3 ). Serum ferritin and hemoglobin levels were assessed on venous blood as previously described. ${ }^{32,33}$

IDA was defined as a simultaneous serum ferritin of $\leq 12 \mathrm{ng} / \mathrm{mL}$ and a hemoglobin of $\leq 11 \mathrm{~g} / \mathrm{dL}$. The value of $\leq 11 \mathrm{~g} / \mathrm{dL}$ of hemoglobin was chosen to allow for the usual mild decrease in hemoglobin concentration seen in normal pregnancies related to the physiologic alterations in blood volume. ${ }^{34-36}$

All adolescent and adult pregnant women who developed IDA at the second test period were offered therapeutic ferrous sulfate containing $60 \mathrm{mg}$ of elemental iron 3 times daily. Most adolescent pregnant women were part of the Healthy Birth Program at St. Joseph's Hospital.

Statistical comparisons between groups with regard to IDA, adherence, and side effects were based upon Fisher's exact test, while comparisons of hemoglobin, serum ferritin, and gestational age were based upon the Wilcoxon rank sum test. Twelve subjects who received therapeutic iron for IDA during the study were analyzed as randomized ( 9 on placebo, 3 on iron). Results in this report are deemed statistically significant $(\mathrm{p}<0.05)$.

\section{RESULTS}

\section{Patients}

Over a study period of 29 months, 144 patients were initially enrolled on the study. Thirty-three patients were ultimately excluded or lost to analysis: 20 had inadequate data or failed to comply with the study or medication requirements (10 were adolescents and 10 were adults); 3 moved or were lost to follow-up; 3 had spontaneous abortions; and 7 were excluded for other reasons. Of the 111 patients analyzed, 53 received placebo and 58 received iron supplementation. Patient characteristics at randomization are shown in table 1 and were well balanced between the randomized groups.

\section{Incidence of anemia in pregnancy}

Overall, 34 of 111 (31\%) women developed IDA, 25 of 53 $(47 \%)$ receiving placebo and 9 of $58(15 \%)$ receiving iron $(\mathrm{p}<0.001)$. In adolescents, 4 of $20(20 \%)$ iron supplemented patients, and 10 of 17 (59\%) receiving placebo developed IDA ( $\mathrm{p}=0.021)$. Among adults, 5 of $38(13 \%)$ receiving iron, and 15 of $36(42 \%)$ receiving placebo developed IDA $(p=0.008)$. Thus, in both age groups the incidence of IDA was significantly reduced in iron treated patients compared to placebo treated patients (table 2). The incidence of IDA was not significantly different comparing adolescent and adult groups ( $38 \%$ vs. $27 \%, \mathrm{p}=0.38)$.
More severe IDA with hemoglobins $<10.0 \mathrm{~g} / \mathrm{dL}$ occurred in four adults ( 1 on iron, 3 on placebo) and two adolescents (both on placebo) during the study. Iron deficiency without anemia was developing in both placebo groups by tests 2 or 3 as evidenced by significantly lower serum ferritin levels (table 3 and figure 1).

\section{Adherence to supplements}

Adherence to supplements was assessed through pill counts, although results were not available in all patients. Adherence was generally high but ranged from $32 \%$ to $124 \%$ in individual patients (table 3 ). In the iron group, this corresponds to a range of 19-74 mg/day in women's average intake of elemental iron during the study period. Among adults, the observed adherence was significantly higher among those taking iron, with medians of $98 \%$ and $84 \%$ among adults taking iron and placebo, respectively $(\mathrm{p}=0.036)$.

\section{Side effects}

Table 4 shows the incidence of side effects for the four studied symptoms. There were no significant differences between iron and placebo treated patients or between the adolescents and adults.

\section{Pregnancy outcomes}

Mean gestational age at the time of delivery was over 39 weeks and was not significantly different between iron and placebo treated patients (table 5). There was no clinically significant perinatal morbidity or mortality among any of the infants delivered as measured by Apgar scores at 1 and 5 minutes. None of the infants needed admission to the neonatal intensive care unit. Only three infants were less than 2,500 $\mathrm{g}$ at birth, one from the iron group and two from the placebo group. The total number of $\mathrm{C}$-sections in all pregnancies was 19 , with similar frequencies in the iron and placebo groups (16\% and $19 \%$, respectively).

\section{Therapeutic iron supplementation}

A therapeutic supplementation of ferrous sulfate $60 \mathrm{mg} 3$ times daily was offered to women who developed IDA during the second trimester (at test 2 on weeks 24 to 28) and was accepted by three women in the iron group and nine women in the placebo group. IDA was resolved by the third test at the end of their pregnancies in all three women in the iron group and in six of nine women in the placebo group. This part of the study was strictly observational and adherence in taking supplemental iron was not measured.

\section{DISCUSSION}

Both adolescent and adult women were shown to have significantly higher rates of IDA during pregnancy if given placebo compared to $60 \mathrm{mg}$ of elemental iron daily. This would suggest that the growth spurt and onset of menses prior to conception in iron sufficient women does not give adequate iron stores to prevent IDA without oral supplemental iron during pregnancy. 
The incidence of IDA in our study was higher in adolescent than adult pregnancies. Although this was not statistically significant, the study had low power to detect an effect of this magnitude, and the difference was observed in both iron and placebo groups (see table 2). The incidence was also much higher than in two non-randomized studies of IDA in adolescent pregnancy in other developed countries, where the incidence varied from $1.5 \%$ in Chile to $14.2 \%$ in Brazil. ${ }^{7,37}$ In developing countries, additional higher risks for severe IDA in adolescent pregnancies include the young age at conception before the extra iron needs of maternal growth have been met, anemias associated with infectious diseases such as malaria, and hemoglobinopathies. ${ }^{38-42}$

As seen in other studies, iron supplementation decreased the incidence of IDA and enhanced iron status during pregnancy. ${ }^{16,19}$ The daily regimen of supplementation resulted in no apparent increase in acute side effects in either group, although the number of women studied limited our ability to detect such effects, and the four symptoms some- times associated with taking iron may be similar to the symptoms of normal pregnancies. Similarly, there was no discernible difference between supplemented and placebo patients in maternal or newborn infant health status upon delivery despite the differences in iron status during pregnancy (table 5).

There are many good reasons to strive to eliminate iron deficiency in adolescents worldwide. ${ }^{43}$ However, our findings suggest that even if iron status is elevated to normal levels, there may still be need for iron supplementation selectively during pregnancy, if the goal is to maintain serum ferritin and hemoglobin levels within normal ranges. For mild to moderate iron deficiency during pregnancy, the importance of this goal to maternal and neonatal health remains unclear.

Whether or not routine iron supplementation is necessary in adult pregnancies has been extensively reviewed. Aside from the benefits of feeling better and having fewer symptoms related to IDA, it is difficult to show benefit for pregnancy outcome or improvement of the health of the mother or

Table 1. Patient characteristics at randomization by age group and treatment.

\begin{tabular}{|c|c|c|c|c|c|c|}
\hline & \multicolumn{3}{|c|}{ Iron } & \multicolumn{3}{|c|}{ Placebo } \\
\hline & $\mathbf{N}$ & Median & Range & $\mathbf{N}$ & Median & Range \\
\hline \multicolumn{7}{|c|}{ Adolescents } \\
\hline Age (years) & 20 & 18.2 & $15-18$ & 17 & 17.7 & $15-18$ \\
\hline Week of pregnancy & 20 & 14.1 & $8-18$ & 16 & 12.1 & 8-18 \\
\hline Serum ferritin $(\mathrm{ng} / \mathrm{mL})$ & 19 & 31.1 & $13-93$ & 17 & 34.0 & $9-151$ \\
\hline Hemoglobin (g/dL) & 20 & 12.6 & $11-14$ & 17 & 13.1 & $11-14$ \\
\hline \multicolumn{7}{|c|}{ Adults } \\
\hline Age (years) & 38 & 25.2 & $18^{\ddagger-35}$ & 36 & 28.8 & $21-39$ \\
\hline Week of pregnancy & 38 & 10.6 & $7-17$ & 36 & 12.3 & $3-17$ \\
\hline Serum ferritin $(\mathrm{ng} / \mathrm{mL})$ & 38 & 39.3 & $6-182$ & 35 & 37.0 & $9-163$ \\
\hline Hemoglobin (g/dL) & 38 & 13.0 & $11-15$ & 36 & 12.9 & $11-17$ \\
\hline
\end{tabular}

Table 2. Incidence of IDA in adolescent and adult pregnancies.

\begin{tabular}{|c|c|c|c|c|c|c|}
\hline \multicolumn{7}{|c|}{ Iron deficiency anemia at test $\mathbf{2}$ or $\mathbf{3}$} \\
\hline & Total Patients & Test 2 & Test 3 & Total & Percent & p-value $\ddagger$ \\
\hline \multicolumn{7}{|c|}{ Adolescents } \\
\hline Iron & 20 & 3 & 1 & 4 & 20 & \\
\hline Placebo & 17 & 5 & 5 & 10 & 59 & 0.021 \\
\hline \multicolumn{7}{|c|}{ Adults } \\
\hline Iron & 38 & 1 & 4 & 5 & 13 & \\
\hline Placebo & 36 & 7 & 8 & 15 & 42 & 0.008 \\
\hline
\end{tabular}

$\ddagger_{p}$-values compare iron to placebo in each group. 
Table 3. Follow-up results by age group and treatment.

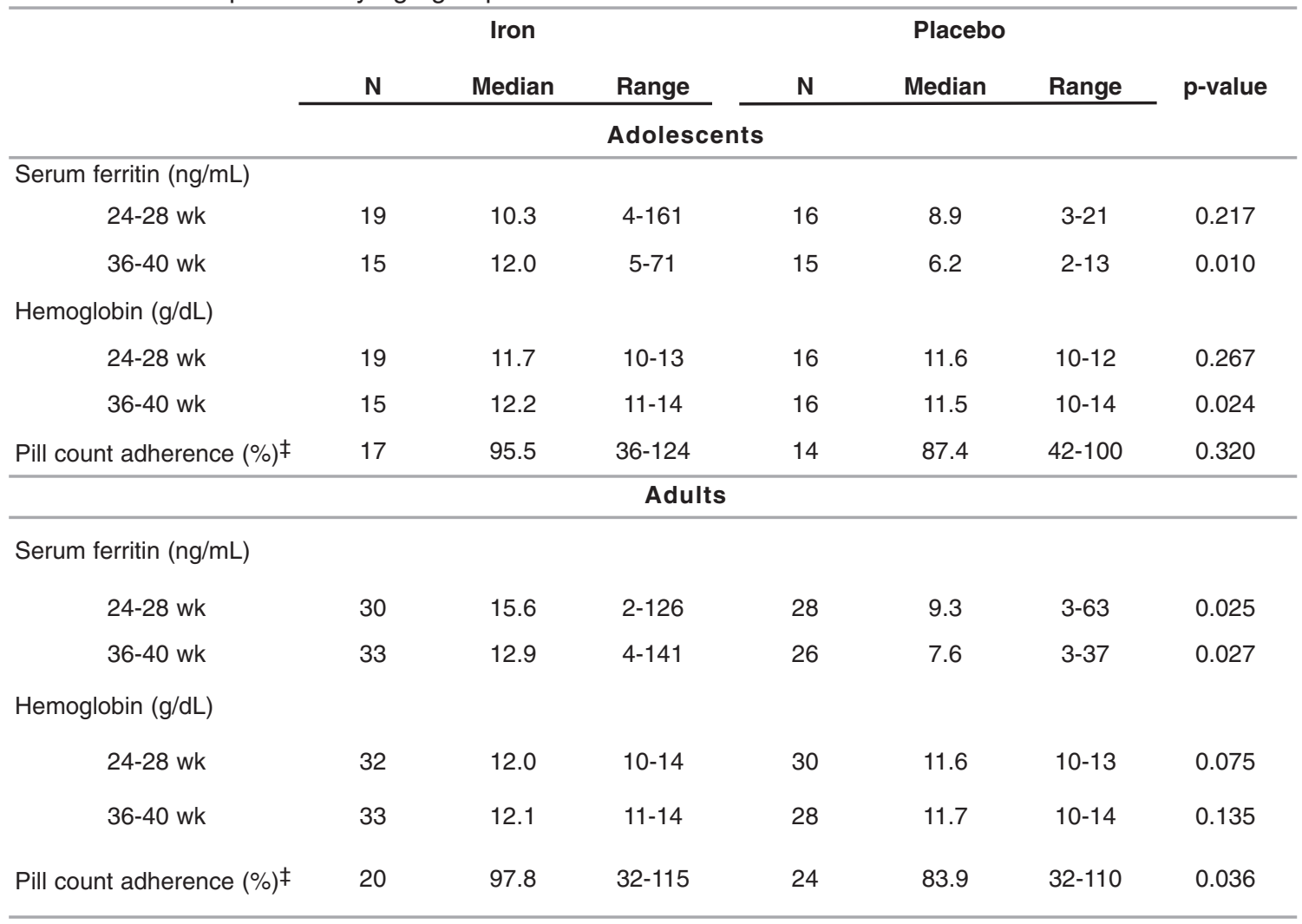

ҒPercent adherence is defined as 100 (225 pill count) / (days on study).

Table 4. Incidence of side effects at any time in the pregnancy.

\begin{tabular}{|c|c|c|}
\hline & Adolescent & Adult \\
\hline \multicolumn{3}{|l|}{ Nausea } \\
\hline Iron & $53 \%$ & $63 \%$ \\
\hline Placebo & $65 \%$ & $53 \%$ \\
\hline \multicolumn{3}{|l|}{ Vomiting } \\
\hline Iron & $41 \%$ & $35 \%$ \\
\hline Placebo & $41 \%$ & $21 \%$ \\
\hline \multicolumn{3}{|l|}{ Constipation } \\
\hline Iron & $29 \%$ & $24 \%$ \\
\hline Placebo & $12 \%$ & $28 \%$ \\
\hline \multicolumn{3}{|l|}{ Diarrhea } \\
\hline Iron & $13 \%$ & $14 \%$ \\
\hline Placebo & $17 \%$ & $24 \%$ \\
\hline
\end{tabular}

No significant differences in iron vs. placebo or adolescents vs. adults.

fetus. ${ }^{44,45}$ However, in our study only $20 \%$ of adolescents and $13 \%$ of adults developed IDA if they were on $60 \mathrm{mg} /$ day of elemental iron. Other research suggests that $65 \mathrm{mg}$ of elemental iron per day in the second trimester is sufficient to prevent iron deficiency in adult pregnancies and may also increase serum ferritins in the cord blood of the newborns. 46
Our study was not large enough to effectively evaluate the potential association of IDA with fetal morbidity and mortality as suggested in some reports. Other studies have shown a larger than 2.5-fold increase in pre-term delivery with IDA. ${ }^{47-50}$ Severe anemia (hemoglobin $<7 \mathrm{~g} / \mathrm{dL}$ ) occurred in $56 \%$ of pregnancies in one developing country, contributing 


\begin{tabular}{|c|c|c|c|c|c|c|}
\hline \multicolumn{7}{|c|}{ Iron deficiency anemia at test $\mathbf{2}$ or $\mathbf{3}$} \\
\hline & $\begin{array}{c}\text { Total } \\
\mathbf{n}\end{array}$ & $\begin{array}{l}\text { Apgar scores of } \\
7 \text { or less in } 1 \\
\text { minute } n(\%)\end{array}$ & $\begin{array}{c}\text { Length } \\
(\mathrm{cm}) \\
\text { Mean } \pm \text { SD }\end{array}$ & $\begin{array}{c}\text { Gestational age } \\
\text { (weeks) } \\
\text { Mean } \pm \text { SD }\end{array}$ & $\begin{array}{c}\text { Birth weight } \\
(<2,500 \mathrm{~g}) \\
\mathrm{n}(\%)\end{array}$ & $\begin{array}{c}\text { C-sections }{ }^{\ddagger} \\
\text { n (\%) }\end{array}$ \\
\hline \multicolumn{7}{|c|}{ Adolescents } \\
\hline Iron & 20 & $6(30.0)$ & $50.0 \pm 2.3$ & $39.9 \pm 1.3$ & $0(0)$ & $4(20.0)$ \\
\hline Placebo & 16 & $4(25.0)$ & $51.6 \pm 1.7$ & $39.8 \pm 1.3$ & $0(0)$ & $1(6.2)$ \\
\hline \multicolumn{7}{|c|}{ Adults } \\
\hline Iron & 38 & $11(29.7)$ & $52.4 \pm 2.5$ & $39.2 \pm 1.7$ & $2(5.4)$ & $5(14.3)$ \\
\hline Placebo & 36 & $6(16.7)$ & $51.8 \pm 2.3$ & $39.5 \pm 1.9$ & $1(2.9)$ & $9(25.0)$ \\
\hline
\end{tabular}

†Two elective repeat C-sections were not included, as they would not be related to adverse effects from pregnancy.
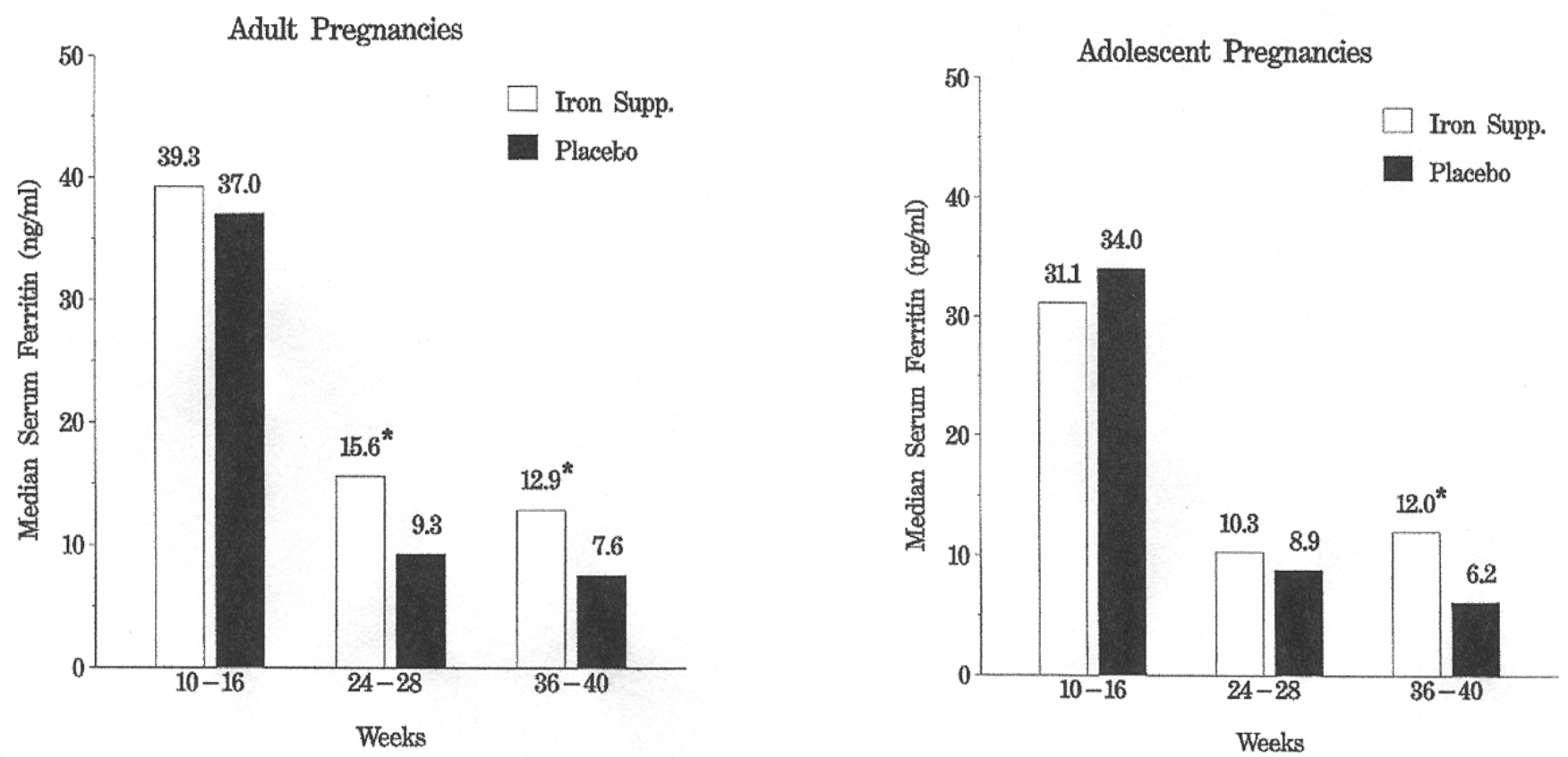

Figure 1. Mean serum ferritin levels $(\mathrm{ng} / \mathrm{mL}$ ) during pregnancy in the study groups. *Indicates iron supplement and placebo groups differ significantly.

significantly to maternal death rates. ${ }^{51}$ Iron treated adult pregnancies have been associated with increased mean length and Apgar scores. ${ }^{52}$ Prophylactic iron supplementation before and during pregnancy reportedly gives the best possible outcome for the mothers and children in developed and developing countries. ${ }^{53-57}$

Our study indicates that $60 \mathrm{mg} /$ day of elemental iron helps to prevent IDA in both adolescent and adult pregnancies.

Furthermore, among 12 women who developed IDA during the second trimester and received therapeutic supplementation with $180 \mathrm{mg}$ of elemental iron daily, 9 of $12(75 \%)$ had resolved the IDA by the end of their pregnancies. Given that the side effects often attributed to iron supplements are similar to those of normal pregnancy, it is hoped that increased adherence in taking iron supplements will allow further success in the treatment of IDA during pregnancy.

\section{ACKNOWLEDGMENTS}

The authors wish to thank Marshfield Medical Research Foundation for its support through the assistance of Alice Stargardt, Doreen Luepke and Graig Eldred, Ph.D. for their assistance in the preparation of this manuscript. 


\section{REFERENCES}

1. Abel R, Rajaratnam J, Kalaimani A, Kirubakaran S. Can iron status be improved in each of the three trimesters? A community-based study. Eur J Clin Nutr 2000;54: 490-493.

2. Allen LH, Rosado JL, Casterline JE, Lopez P, Munoz E, Garcia OP, Martinez H. Lack of hemoglobin response to iron supplementation in anemic Mexican preschoolers with multiple micronutrient deficiencies. Am J Clin Nutr 2000;71: 1485-1494.

3. Baynes RD, Cook JD. Current issues in iron deficiency. Curr Opin Hematol 1996;3: 145-149.

4. Beard JL. Weekly iron intervention: the case for intermittent iron supplementation. Am J Clin Nutr 1998;68: 209-212.

5. Brabin BJ, Hakimi M, Pelletier D. An analysis of anemia and pregnancyrelated maternal mortality. J Nutr 2001;131: 604S-614S.

6. Dillon JC. Prevention of iron deficiency and iron deficiency anemia in tropical areas. Med Trop (Mars) 2000;60: 83-91.

7. Fujimori E, de Oliveira IM, de Cassana LM, Szarfarc SC. Iron nutritional status in pregnant adolescents, Sao Paulo, Brazil. Arch Latinoam Nutr 1999;49: 8-12.

8. Gadowsky SL, Gale K, Wolfe SA, Jory J, Gibson R, O’Connor DL. Biochemical folate, B12, and iron status of a group of pregnant adolescents accessed through the public health system in southern Ontario. J Adolesc Health 1995;16: 465-474.

9. Geissler PW, Shulman CE, Prince RJ, Mutemi W, Mnazi C, Friis H, Lowe B. Geophagy, iron status and anemia among pregnant women on the coast of Kenya. Trans R Soc Trop Med Hyg 1998;92: 549-553.

10. Milman N, Bergholt T, Eriksen L, Ahring K, Graudal NA. Iron requirements and iron balance during pregnancy. Is iron supplementation needed for pregnant women? Ugeskr Laeger 1997;159: 6057-6062.

11. Milman N, Bergholt T, Byg KE, Eriksen L, Graudal N. Iron status and iron balance during pregnancy. A critical reappraisal of iron supplementation. Acta Obstet Gynecol Scand 1999;78: 749-757.

12. Pita Martin de Portela ML, Langini SH, Fleischman S, et al. Effect of iron supplementation and its frequency during pregnancy. Medicina (B Aires) 1999;59: 430-436.

13. Preziosi P, Prual A, Galan P, Daouda H, Boureima H, Hercberg S. Effect of iron supplementation on the iron status of pregnant women: consequences for newborns. Am J Clin Nutr 1997;66: 1178-1182.

14. Quintas ME, Requejo AM, Ortega RM, Redondo MR, Lopez-Sobaler AM, Gaspar MJ. The female Spanish population: a group at risk of nutritional iron deficiency. Int J Food Sci Nutr 1997;48: 271-279.

15. Roodenburg AJ. Iron supplementation during pregnancy. Eur J Obstet Gynecol Reprod Biol 1995;61: 65-71.

16. Zavaleta N, Respicio G, Garcia T. Efficacy and acceptability of two iron supplementation schedules in adolescent school girls in Lima, Peru. J Nutr 2000;130: 462S-464S.

17. Allen LH. Anemia and iron deficiency: effects on pregnancy outcome. Am J Clin Nutr 2000;71: 1280S-1284S.

18. Beaufrere B, Bresson JL, Briend A, Farriaux JP, Ghisolfi J, Navarro J, Rey J, Ricour C, Rieu D, Vidailhet M. Iron and pregnancy. Arch Pediatr 1995;2: 1209-1218.

19. Lynch SR. The potential impact of iron supplementation during adolescence on iron status in pregnancy. J Nutr 2000;130: 448S-451S.

20. Scholl TO, Reilly T. Anemia, iron and pregnancy outcome. J Nutr 2000;130: 443S-447S

21. Schwartz WJ $3^{\text {rd }}$, Thurnau GR. Iron deficiency anemia in pregnancy. Clin Obstet Gynecol 1995;38: 443-454.

22. Beard JL. Iron deficiency: assessment during pregnancy and its importance in pregnant adolescents. Am J Clin Nutr 1994;59: 502S-508S

23. DeMaeyer EM, Dallman P, Gurney JM, Hallberg L, Sood SK, Srikantia SG. Preventing and controlling iron deficiency anaemia through primary health care: a guide for health administrators and programme managers. Geneva, Switzerland: World Health Organization, 1989.

24. World Bank. World Development Report 1993. Investing in Health. New York: Oxford University Press, 1993.

25. Ronsmans C, Achadi E, Sutratikto G, Zazri A, McDermott J. Use of hospital data for Safe Motherhood programmes in south Kalimantan, Indonesia. Trop Med Int Health 1999;4: 514-521.

26. World Health Organization. Adolescent nutrition: a neglected dimension. http://www.who.int/nut/ado.htm (5/31/01)

27. Kurz KM, Galloway R. Improving adolescent iron status before childbearing. J Nutr 2000;130: 437S-439S.

28. Barrett JF, Whittaker PG, Williams JG, Lind T. Absorption of non-haem iron from food during normal pregnancy. Br Med J 1994;309: 79-82.
29. Dallman PR. Changing iron needs from birth through adolescence. In: Fomon SJ, Zlotkin S, editors. Nutritional Anemias. Nestle Nutrition Workshop Series, Vol. 30, Nestec Ltd. New York, NY: Vevey/Raven Press; 1992. p. 29-38.

30. World Health Organization. Young people's health - A challenge for society. WHO Technical Report Series, no. 731, Geneva, Switzerland: WHO. 1986

31. Huber AM, Wallins LL, DeRusso P. Folate nutriture in pregnancy. J Am Diet Assoc 1988;88: 791-795.

32. Nickerson HJ, Holubets M, Tripp AD, Pierce WE. Decreased iron stores in high school female runners. Am J Dis Child 1985;139: 1115-1119.

33. Nickerson HJ, Holubets MC, Weiler BR, Haas RG, Schwartz S, Ellefson ME. Causes of iron deficiency in adolescent athletes. J Pediatr 1989;114: 657-663.

34. Fenton V, Cavill I, Fisher J. Iron stores in pregnancy. Br J Haematol 1977;37: 145-149.

35. Cook JD, Finch CA. Assessing iron status of a population. Am J Clin Nutr 1979;32: 2115-2119.

36. Committee on Nutritional Status During Pregnancy and Lactation, Institute of Medicine. Nutrition during pregnancy: Part I: weight gain, Part II: nutrient supplements. Washington DC: National Academy Press, 1990.

37. Sloan NL, Jordan E, Winikoff B. Effects of iron supplementation on maternal hematologic status in pregnancy. Am J Public Health 2002;92: 288-293.

38. Menendez C, Todd J, Alonso PL, Francis N, Lulat S, Ceesay S, M'Boge $\mathrm{B}$, Greenwood BM. The effects of iron supplementation during pregnancy, given by traditional birth attendants, on the prevalence of anaemia and malaria. Trans R Soc Trop Med Hyg 1994;88: 590-593.

39. Pappagallo S, Bull DL. Operational problems of an iron supplementation programme for pregnant women: an assessment of UNRWA experience. Bull World Health Organ 1996;74: 25-33.

40. Diejomaoh FM, Abdulaziz A, Adekile AD. Anemia in pregnancy. Int J Gynaecol Obstet 1999;65: 299-301.

41. Kapil U, Saxena N, Ramachandran S. Iron deficiency anemia in pregnancy. Indian Pediatr 1996;33: 606.

42. Fleming AF, Briggs ND, Rossiter CE. Growth during pregnancy in Nigerian teenage primigravidae. Br J Obstet Gynaecol 1985;9: 32-39.

43. Bruner AB, Joffe A, Duggan AK, Casella JF, Brandt J. Randomised study of cognitive effects of iron supplementation in non-anaemic iron-deficient adolescent girls. Lancet 1996;348: 992-996.

44. Scholl TO, Hediger ML. Anemia and iron-deficiency anemia: compilation of data on pregnancy outcome. Am J Clin Nutr 1994;59: 492S$501 \mathrm{~S}$

45. Routine iron supplementation during pregnancy. Review article. US Preventive Services Task Force. JAMA 1993;270: 2848-2854.

46. Milman N, Agger AO, Nielsen OJ. Iron status markers and serum erythropoietin in 120 mothers and newborn infants. Effect of iron supplementation in normal pregnancy. Acta Obstet Gynecol Scand 1994;73: 200-204.

47. Scholl TO, Hediger ML, Fischer RL, Shearer JW. Anemia vs iron deficiency: increased risk of preterm delivery in a prospective study. Am J Clin Nutr 1992;55: 985-988.

48. Rasmussen KM. Is there a causal relationship between iron deficiency or iron-deficiency anemia and weight at birth, length of gestation and perinatal mortality? J Nutr 2001;131: 590S-601S; discussion 601S$603 \mathrm{~S}$

49. MacGregor MW. Maternal anaemia as a factor in prematurity and perinatal mortality. Scot Med J 1963;8: 134-140.

50. Brabin BJ, Hakimi M, Pelletier D. An analysis of anemia and pregnancyrelated maternal mortality. J Nutr 2001;131: 604S-615S; discussion 614S-615S.

51. Sarin AR. Severe anemia of pregnancy, recent experience. Int J Gynaecol Obstet 1995;50(suppl 2): S45-S49.

52. Preziosi P, Prual A, Galan P, Daouda H, Boureima H, Hercberg S. Effect of iron supplementation on the iron status of pregnant women: consequences for newborns. Am J Clin Nutr 1997;66: 1178-1182.

53. Kurz KM, Galloway R. Improving adolescent iron status before childbearing. J Nutr 2002;130: 437S-439S.

54. Lynch SR. The potential impact of iron supplementation during adolescence on iron status in pregnancy. J Nutr 2000;130(2S suppl): 448S$451 \mathrm{~S}$

55. Milman N, Bergholt T, Byg KE, Eriksen L, Graudal N. Iron status and iron balance during pregnancy. A critical reappraisal of iron supplementation. Acta Obstet Gynecol Scand 1999;78: 749- 
56. Looker AC, Dallman PR, Carroll MD, Gunter EW, Johnson CL.

Prevalence of iron deficiency in the United States. JAMA 1997;277: 973-976.

57. Abel R, Rajaratnam J, Kalaimani A, Kirubakaran S. Can iron status be improved in each of the three trimesters? A community-based study. Eur J Clin Nutr 2000;54: 490-493. 